\title{
Stability Analysis of a Direct-Operated Seawater Hydraulic Relief Valve under Deep Sea
}

\author{
Shan $\mathrm{Wu}^{1,2}$ Chao $\mathrm{Li}^{2}$ and Yipan Deng ${ }^{2}$ \\ ${ }^{1}$ Department of Public Basic Course, Wuhan Technology and Business University, Wuhan, Hubei 430065, China \\ ${ }^{2}$ School of Mechanical Science and Engineering, Huazhong University of Science and Technology, Wuhan 430074, China \\ Correspondence should be addressed to Chao Li; lichaobxd@hust.edu.cn
}

Received 16 February 2017; Revised 10 April 2017; Accepted 16 April 2017; Published 16 May 2017

Academic Editor: Oleg V. Gendelman

Copyright (c) 2017 Shan Wu et al. This is an open access article distributed under the Creative Commons Attribution License, which permits unrestricted use, distribution, and reproduction in any medium, provided the original work is properly cited.

\begin{abstract}
Taking into account the deformation of a designed direct-operated seawater hydraulic relief valve in deep sea, which might have a great influence on the stability of the valve, a mathematic model of the relief valve was established and stability analysis was conducted. As the fitting clearances between the damping sleeve and the damping bar play a key role in the performance of the relief valve, the fitting clearances after deformation under pressure of different ocean depths were obtained using finite element method. Applying the deformation data to the relief valve model, the stability and relative stability could be analyzed quantitatively through both the frequency domain analysis method and the time domain analysis method to detect the influence of the fitting clearance after deformation. The simulation results show that the seawater relief valve has a stable performance within 4000 meters deep under the sea.
\end{abstract}

\section{Introduction}

The traditional hydraulic technology takes mineral oil as its working medium. By contrast, the seawater hydraulic technology which takes seawater directly as a medium has a lot of advantages, including no pollution of leakage, simple structure, and easy maintenance, and thus it has a wide range of applications in deep-sea equipment. In recent years, seawater hydraulics have been successfully applied to walking/propulsion systems [1], buoyancy adjusting systems [2,3], operating systems [4], and other key subsystems of marine equipment, and the researches focus mostly on matching materials [5-8] and water hydraulic components [9]. As a consequence, water hydraulics have become internationally the focus of attention in the field of fluid power transmission and control.

Almost every hydraulic system is equipped with a pressure relief valve to maintain the working pressure of the system at a predetermined level and protect the system from overpressure. There are two kinds of relief valves that are available: direct-operated (one-stage) [10] and pilot type [11]. Compared with the pilot-operated relief valve, the structure of the direct-operated type is simpler, and the operation is more stable and reliable [12]. Besides, for the direct-operated type, the leakage is less and the sealing is relatively easier. Therefore, such direct-operated relief valve using seawater as the working medium is frequently used [13]. However, the features of both physical and chemical performances of water are totally different from oil. The density of water is larger than that of oil. When the temperature is $20^{\circ} \mathrm{C}$, the viscosity of seawater is $1.0 \times 10^{-3} \mathrm{~Pa} \cdot \mathrm{s}$, about $1 / 30-1 / 50$ of the viscosity of commonly used hydraulic oil. The elastic modulus of water is about 1.2 times as much as that of oil $[14,15]$. Due to these factors, the vibration and impact problem are highlighted for the water relief valve [16]. Adding a damping device is often used to reduce vibration and impact $[10,16,17]$.

There are two common methods to analyze the dynamic characteristics of the hydraulic valves, that is, time domain analysis and frequency domain analysis. The results are more intuitionistic to use time domain analysis to simulate a hydraulic valve. Darby [18] and Hos et al. [19] conducted time response analysis for pressure relief valves in gas service, which can clearly show the dynamic response of a relief valve over time. In addition, as a method of frequency domain 


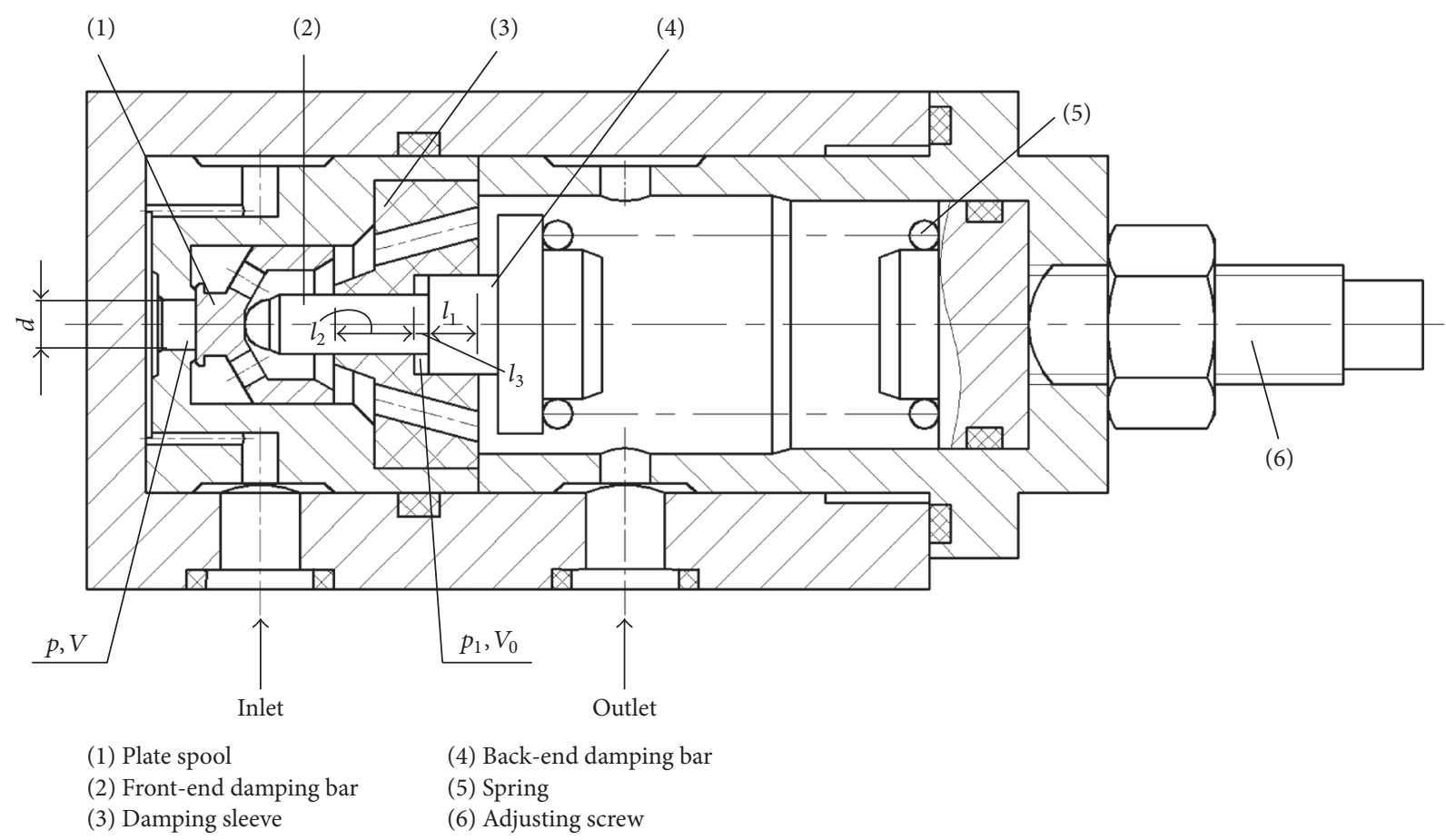

FIGURE 1: Structure schematic diagram of direct-operated seawater relief valve.

analysis, the bond diagram is usually used to analyze the characteristics of the hydraulic valves, such as Dasgupta's research on a proportional solenoid controlled piloted relief valve [20] and Zanj's research on an indirect hydrocontrol valve [21]. However, the deep-sea environment is greatly different from the environment of sea surface. It is characterized by high hydrostatic pressure (pressure increases by 1 atm for every $10 \mathrm{~m}$ in depth). This will make hydraulic components produce large deformation [22], which has a serious effect on the dynamic characteristics of the relief valve. In order to analyze the stability of the direct-operated seawater hydraulic relief valve under different ocean depths, this paper first uses a FEM (finite element method) technique to obtain the fitting clearance deformation under different hydrostatic pressures. Based on the deformation data, the state-space method and modern control theory, which can determine the stability of a linear system, are used to predict the stable operation of the direct-operated seawater hydraulic relief valve. In the end, the time response analysis is conducted to detect the dynamic performance of the relief valve.

Figure 1 shows the structure of the direct-operated seawater hydraulic relief valve studied in this paper. A damping cavity consists of a damping bar and a damping sleeve, which can minimize the vibration of plate spool. Its main structural parameters are shown in Table 1 . While working in the submarine environment, the pressure of large ocean depth will lead to deformation of fitting clearances between the damping bar and the damping sleeve and will have an influence on the stability of the relief valve. In this paper, the $3 \mathrm{D}$ model of the valve is established to calculate the fitting clearance deformation under the ocean environment with FEM. On the basis of the deformation data, the state-space equation and TF (transfer function) are used to quantitatively analyze the stability and relative stability of the valve operating under different ocean depths.

\section{Mathematical Model}

2.1. Basic Model of Relief Valve. In order to simplify the analysis, the following assumptions are made:

(1) When the spool valve is moving, there are no considerations on friction and instantaneous hydraulic dynamics.

(2) The influence of fluid mass is ignored.

(3) The ambient pressure is considered as zero to analyze the performance. This is because the pressure compensated method is often taken in the deep-sea hydraulic system. When the relief valve is used in deep-sea equipment, the pressure difference of the valve between the input and the output is the same as that in land. Consequently, the force acting on the spool due to ambient pressure of the input and output is balanced. Thus, the ambient pressure does not have an influence on the analysis.

(4) The gap width between the damping bar and the damping sleeve is uniform.

(5) The transient flow force is generally disregarded in relief valves because of a much smaller part in various forces, and it is only considered in servo valves and proportional valves.

(6) $l_{1}, l_{2}$, and $l_{3}$ are taken as constant. This is because the stroke of the spool is relatively smaller than the 
TABLE 1: Main structure parameters of the relief valve.

\begin{tabular}{|c|c|c|}
\hline Physical quantity & Sign & Value selection \\
\hline Valve port flow coefficient & $C_{q}$ & 0.8 \\
\hline Seawater dynamic viscosity $(\mathrm{Pa} \cdot \mathrm{s})$ & $\mu$ & 0.001 \\
\hline $\begin{array}{l}\text { Elasticity modulus of seawater } \\
\text { bulk }(\mathrm{MPa})\end{array}$ & $\beta$ & 1780 \\
\hline $\begin{array}{l}\text { Diameter of front section of } \\
\text { damping bar }(\mathrm{mm})\end{array}$ & $d_{1}$ & 10 \\
\hline $\begin{array}{l}\text { Initial fitting clearance of front } \\
\text { section of damping bar (mm) }\end{array}$ & $\delta_{1}$ & 0.02 \\
\hline $\begin{array}{l}\text { Matched length of front section } \\
\text { of damping bar ( } \mathrm{mm})\end{array}$ & $l_{1}$ & 6.5 \\
\hline $\begin{array}{l}\text { Initial length of damping cavity } \\
(\mathrm{mm})\end{array}$ & $l_{3}$ & 3 \\
\hline $\begin{array}{l}\text { Pressure value of working point } \\
\text { (MPa) }\end{array}$ & $p_{s}$ & 14 \\
\hline $\begin{array}{l}\text { Precompressed spring length } \\
(\mathrm{mm})\end{array}$ & $x_{0}$ & 10.28 \\
\hline $\begin{array}{l}\text { Pipeline volume from pump } \\
\text { outlet to valve inlet (L) }\end{array}$ & $V$ & 2 \\
\hline Valve port speed coefficient & $C_{v}$ & 0.8 \\
\hline Seawater density $\left(\mathrm{kg} \cdot \mathrm{m}^{-3}\right)$ & $\rho$ & 1025 \\
\hline Diameter of valve port (mm) & $d$ & 6 \\
\hline $\begin{array}{l}\text { Contact surface diameter of back } \\
\text { section of damping bar ( } \mathrm{mm})\end{array}$ & $d_{2}$ & 6 \\
\hline $\begin{array}{l}\text { Initial fitting clearance of back } \\
\text { section of damping bar (mm) }\end{array}$ & $\delta_{2}$ & 0.02 \\
\hline $\begin{array}{l}\text { Matched length of back section } \\
\text { of damping bar ( } \mathrm{mm})\end{array}$ & $l_{2}$ & 8 \\
\hline $\begin{array}{l}\text { Equivalent mass of moving parts } \\
(\mathrm{g})\end{array}$ & $m$ & 40 \\
\hline $\begin{array}{l}\text { Stiffness coefficient of spring } \\
\left(\mathrm{N} \cdot \mathrm{mm}^{-1}\right)\end{array}$ & $k$ & 34.59 \\
\hline $\begin{array}{l}\text { Working point spring } \\
\text { compression variation }(\mathrm{mm})\end{array}$ & $x_{s}$ & 0.20 \\
\hline Pump outlet flow $\left(\mathrm{L} \cdot \mathrm{min}^{-1}\right)$ & $\Delta q$ & 30 \\
\hline
\end{tabular}

matched length. Thus, the change of matched length will have a little influence on the performance of the valve.

Under the condition of the above assumptions, the mathematical model of seawater hydraulic relief valve (as shown in Figure 2) can be expressed by the following equations $[10,11,16,20,23]$ :

(1) Flow equation of valve port:

$$
q_{m}=C_{q} \pi d x \sqrt{\frac{2 p}{\rho}},
$$

where $q_{m}$ is the flow through the valve port and $p$ is the inlet pressure of valve port.

(2) Differential equation of valve spool movement:

$$
\begin{gathered}
m \ddot{x}+\left(B_{1}+B_{2}\right) \dot{x}+k\left(x+x_{0}\right) \\
=p A+p_{1}\left(A_{1}-A_{2}\right)-F_{\mathrm{ff}},
\end{gathered}
$$

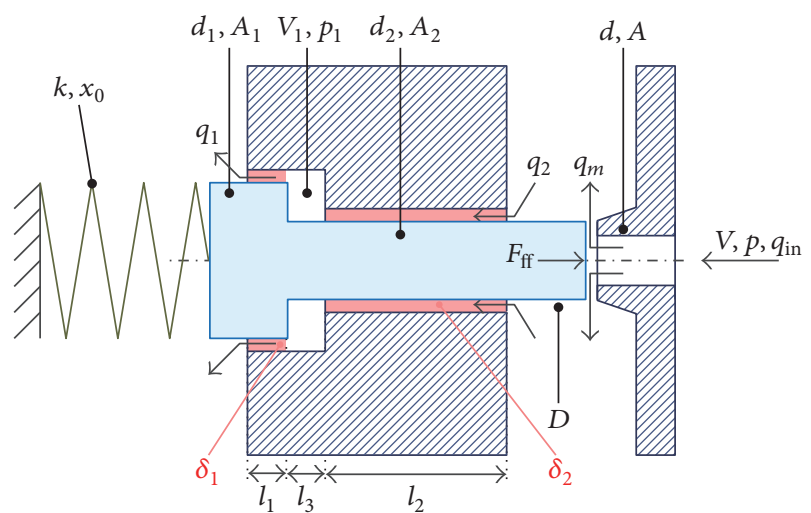

FIGURE 2: Schematic diagram of direct-operated seawater relief valve with damping cavity.

where $p_{1}$ is the pressure of damping cavity; $A, A_{1}$, and $A_{2}$ are, respectively, the flow area of the valve seat, sectional area of the back end of the damping bar, and sectional area of the front end of the damping bar; $B_{1}$ and $B_{2}$ are the damping coefficients of movement, respectively, for the back and front end of the damping bar; that is, $B_{i}=\pi \mu d_{i} l_{i} / \delta_{i}(i=1,2) ; F_{\mathrm{ff}}$ denotes the steady-state flow force generated by the change of speed and direction of the flow through the valve port, and $F_{\mathrm{ff}}=\pi C_{q} C_{v} d x p[24]$.

(3) Continuity equation of valve port:

$$
q_{\text {in }}=q_{m}+A \dot{x}+\frac{V}{\beta} \dot{p},
$$

where $q_{\text {in }}$ is the pump output flow.

(4) Flow equation of damping cavity [25]:

$$
\begin{aligned}
& q_{1}=\frac{\pi d_{1} \delta_{1}^{3}}{12 \mu l_{1}} p_{1} \\
& q_{2}=\frac{\pi d_{2} \delta_{2}^{3}}{12 \mu l_{2}} p_{1},
\end{aligned}
$$

where $q_{1}$ is the clearance flow of the back end of the damping bar and $q_{2}$ is the clearance flow of the front end of the damping bar.

(5) Continuity equation of damping cavity:

$$
q_{1}+q_{2}+\left(A_{1}-A_{2}\right) \dot{x}=-\frac{V_{1}}{\beta} \dot{p}_{1},
$$

where $V_{1}$ is the initial volume of damping cavity; that is, $V_{1}=$ $\pi\left(d_{1}^{2}-d_{2}^{2}\right) l_{3} / 4$.

\subsection{Fitting Clearance Deformation of the Damping Bar under} the Pressure of Large Depth. Under the high pressure of large depth, the fitting clearance between the damping bar and the damping sleeve will become smaller, which has a great influence on the dynamic characteristics of the seawater relief valve. To get fitting clearances at different ocean depths, structural static analyses of the damping sleeve and bar are made by ANSYS Workbench. 

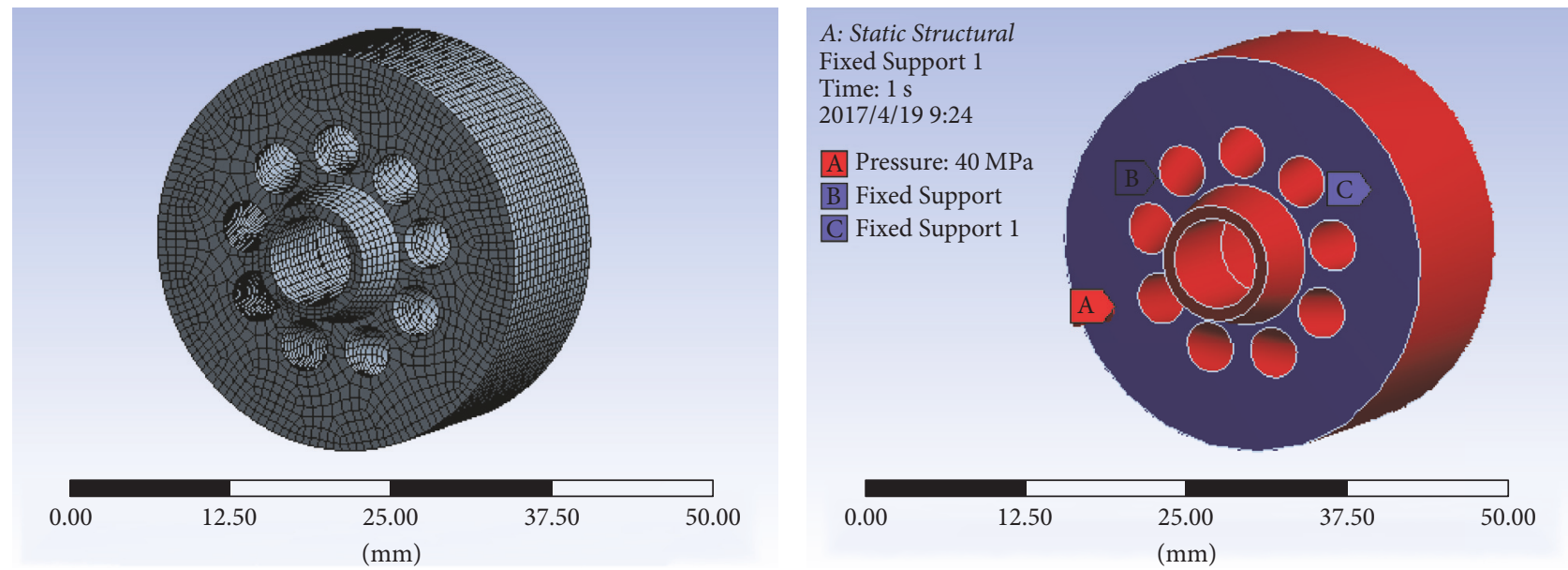

(a) Simulation model of the damping sleeve
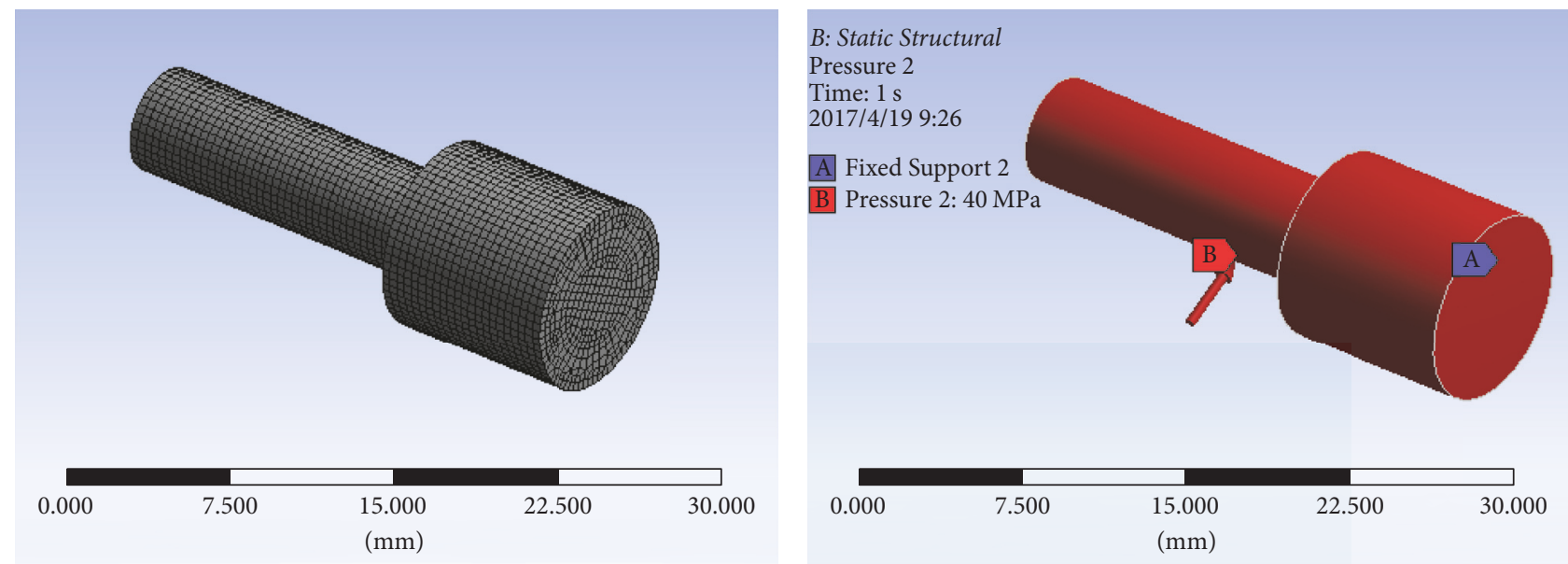

(b) Simulation model of the damping bar

FIGURE 3: Simulation model of fitting clearance deformation of the damping sleeve and bar.

Figure 3 shows the finite element simulation model of the damping sleeve and bar, whose materials are, respectively, PEEK and ANSI 316 Stainless Steel. According to the actual operation condition (as shown in Figure 1), both ends of the damping sleeve and the bottom of the damping bar are fixed. These two parts are wholly steeped in seawater, so ocean depth pressure is added to all faces of the two parts. Then, the fitting clearances at different depths can be obtained.

Figure 4 shows the deformation cloud on the damping sleeve and bar at the depth of $4000 \mathrm{~m}$, respectively. As can be seen from the picture, the deformation of the damping bar is relatively smaller than that of the damping sleeve. Thus, the deformation of the damping sleeve is the major part of the fitting clearance deformation.

The predetermined clearances in land between the damping sleeve and both ends of the damping bar are $\delta_{1}=$ $0.02 \mathrm{~mm}$ and $\delta_{2}=0.02 \mathrm{~mm}$, respectively. And the variation of fitting clearances (as shown in Figure 5) of the front end and back end at different ocean depths can be obtained by finite element simulation. When the ocean depth is $4000 \mathrm{~m}$, the fitting clearance of the damping sleeve and the front end of the damping bar decreases to $0 \mathrm{~mm}$ under huge seawater pressure, which means failure for the valve. Therefore, the discussion of the stability in this paper is all within the ocean depth of $4000 \mathrm{~m}$.

\section{Analysis of Stability Characteristics}

Taking the deformation at different ocean depths into account, qualitative and quantitative analysis of stability and relative stability for this relief valve will be carried out, respectively.

3.1. Stability Analysis. In order to facilitate analysis, the following variables are defined:

$$
\begin{aligned}
& k_{1}=c_{q} \pi d \sqrt{\frac{2}{\rho},} \\
& k_{2}=\pi c_{q} c_{d} d, \\
& k_{3}=\frac{\pi d_{1}}{12 \mu l_{1}},
\end{aligned}
$$




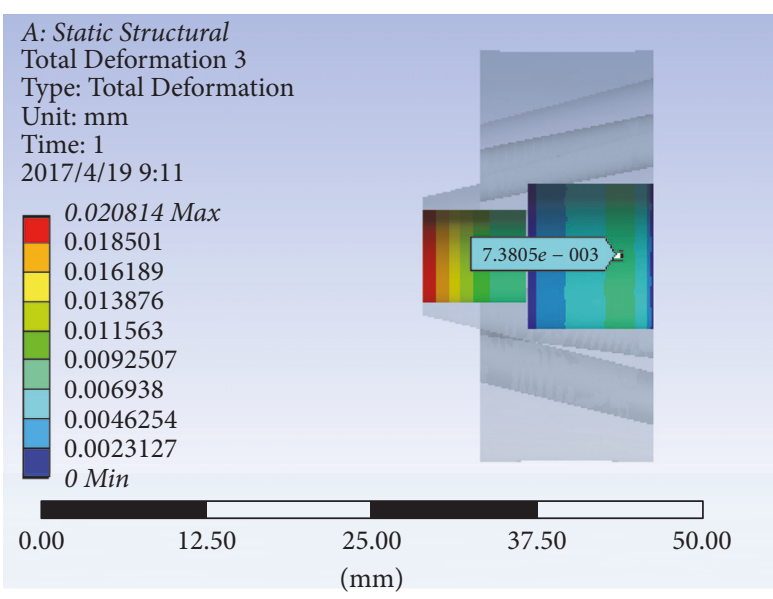

(a) Deformation of the damping sleeve

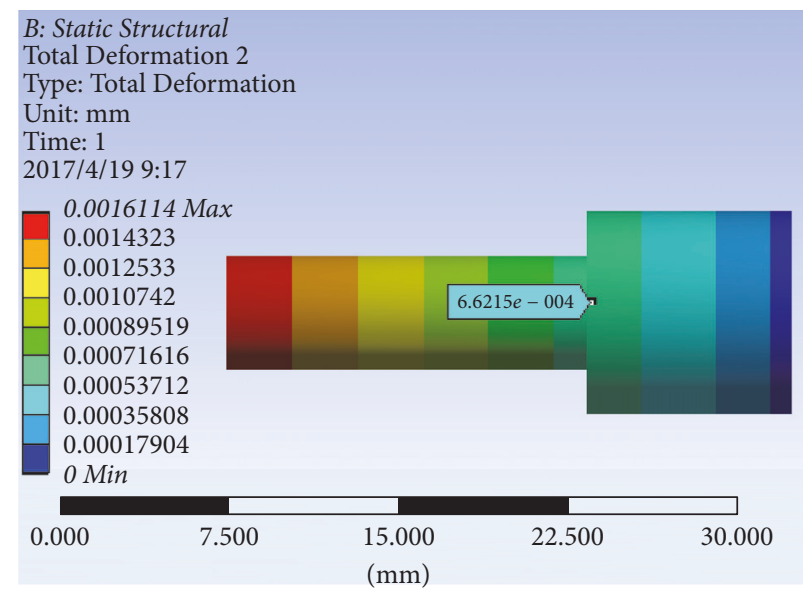

(b) Deformation of the damping bar

FIGURE 4: Deformation of the damping sleeve and damping bar at the depth of $4000 \mathrm{~m}$.

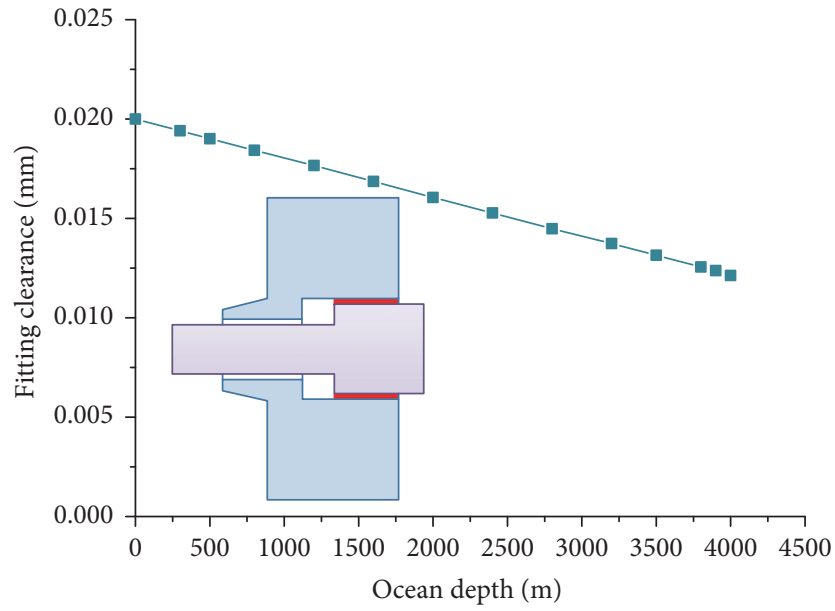

(a) Fitting clearances of back end

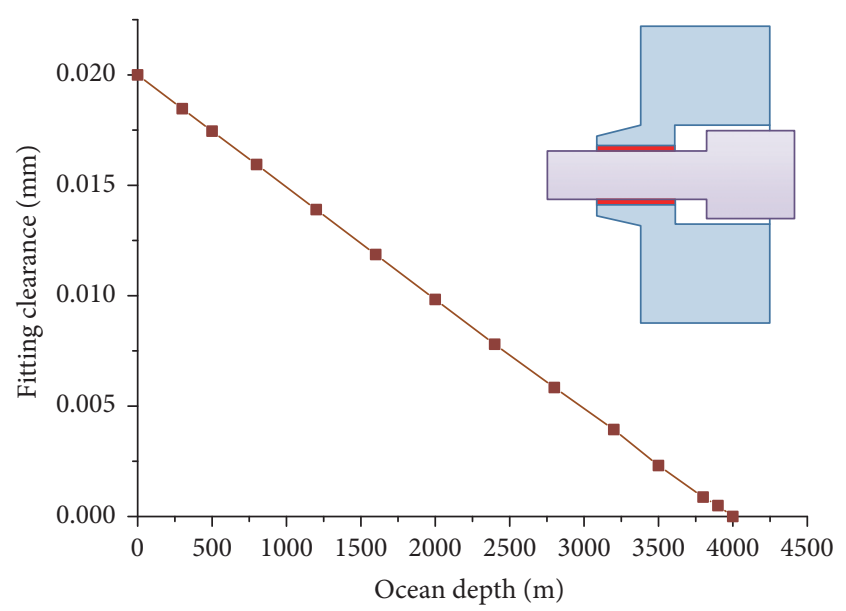

(b) Fitting clearances of front end

FIGURE 5: Variation of damping fitting clearances at different ocean depths.

$$
\begin{aligned}
& k_{4}=\frac{\pi d_{2}}{12 \mu l_{2}}, \\
& B_{1}^{\prime}=B_{1} \delta_{1}, \\
& B_{2}^{\prime}=B_{2} \delta_{1} .
\end{aligned}
$$

Defining $x_{1}=p, x_{2}=\dot{x}, x_{3}=p_{1}$, and $x_{4}=x$ and expanding the system around the normal working point $\left(x_{s}, p_{s}\right)$, the model above can be expressed as

$$
\begin{aligned}
\dot{x}_{1}= & \dot{p} \\
= & -\frac{k_{1} x_{s} \beta}{2 V \sqrt{p_{s}}} x_{1}-\frac{A \beta}{V} x_{2}-\frac{k_{1} \sqrt{p_{s}} \beta}{V} x_{4} \\
& +\frac{\beta}{V} \frac{2 \Delta q+k_{1} x_{s} \sqrt{p_{s}}}{2}
\end{aligned}
$$

$$
\begin{aligned}
\dot{x}_{2}= & \ddot{x} \\
= & \frac{A-k_{2} x_{s}}{m} x_{1}-\frac{B_{1}^{\prime} / \delta_{1}+B_{2}^{\prime} / \delta_{2}}{m} x_{2}+\frac{A_{1}-A_{2}}{m} x_{3} \\
& -\frac{k+k_{2} p_{s}}{m} x_{4}+\frac{k_{2} x_{s} p_{s}-k x_{0}}{m} ; \\
\dot{x}_{3}= & \dot{p}_{1}=-\frac{\left(A_{1}-A_{2}\right) \beta}{V_{1}} x_{2}-\frac{\left(k_{3} \delta_{1}^{3}+k_{4} \delta_{2}^{3}\right) \beta}{V_{1}} x_{3} ; \\
\dot{x}_{4}= & \dot{x}=x_{2} .
\end{aligned}
$$

And then, to order $f_{1}=k_{2} x_{s} p_{s}-k x_{0}, f_{2}=\left(2 q_{\text {in }}+k_{1} x_{s} \sqrt{p_{s}}\right) / 2$, a state-space equation of the relief valve can obtained:

$$
\begin{aligned}
& \mathbf{X}=\mathbf{A} \dot{\mathbf{X}}+\mathbf{B F}, \\
& \mathbf{Y}=\mathbf{C X}+\mathbf{D F},
\end{aligned}
$$




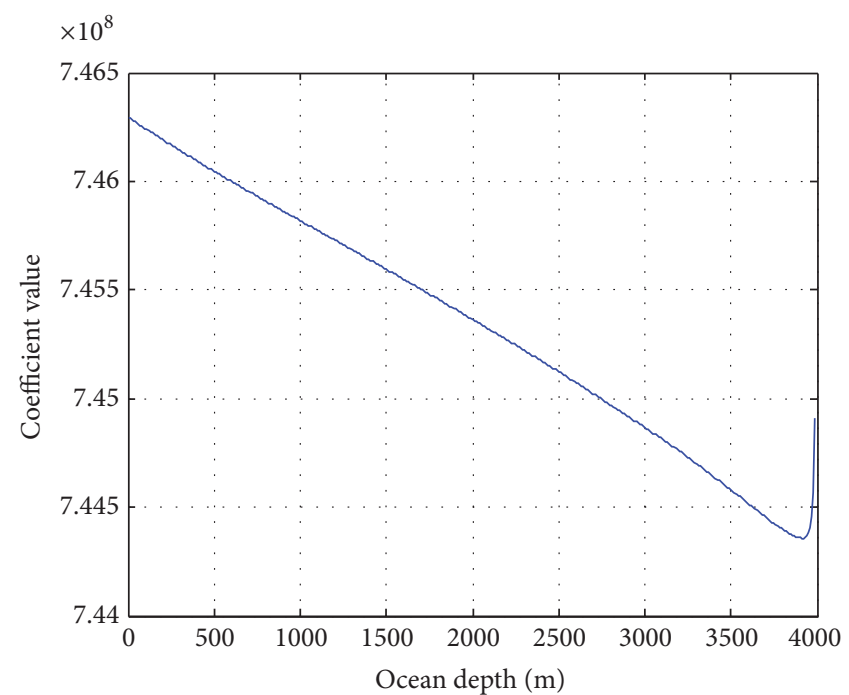

(a) Coefficient value in the first column of $s^{2}$

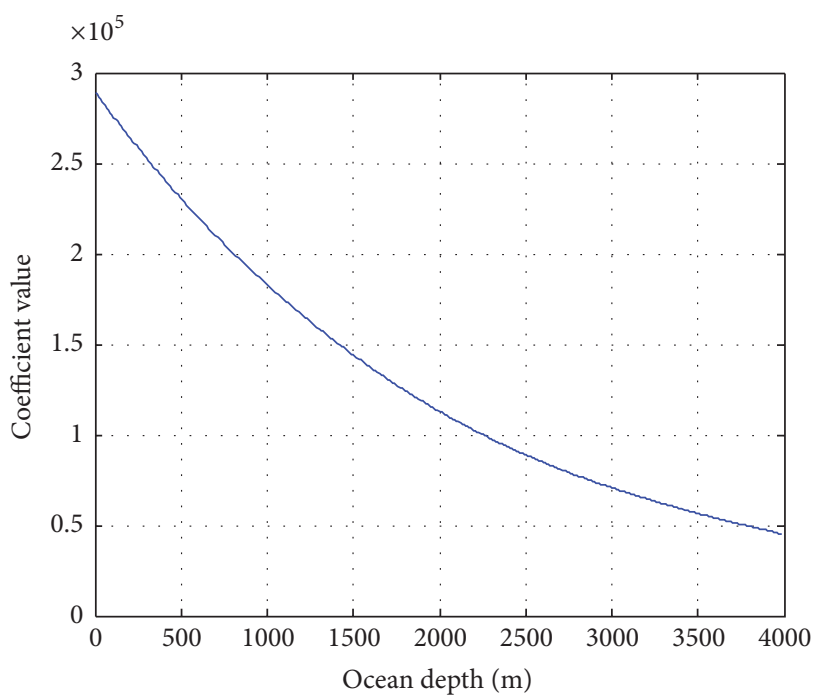

(b) Coefficient value in the first column of $s^{1}$

FIGURE 6: Values of the first column coefficient in Routh Table with different ocean depths.

where

A

$$
\begin{aligned}
& =\left[\begin{array}{cccc}
-\frac{k_{1} x_{s} \beta}{2 V \sqrt{p_{s}}} & -\frac{A \beta}{V} & 0 & -\frac{k_{1} \sqrt{p_{s}} \beta}{V} \\
\frac{A-k_{2} x_{s}}{m} & -\frac{B_{1}^{\prime} / \delta_{1}+B_{2}^{\prime} / \delta_{2}}{m} & \frac{A_{1}-A_{2}}{m} & -\frac{k+k_{2} p_{s}}{m} \\
0 & -\frac{\left(A_{1}-A_{2}\right) \beta}{V_{1}} & -\frac{\left(k_{3} \delta_{1}^{3}+k_{4} \delta_{2}^{3}\right) \beta}{V_{1}} & 0 \\
0 & 1 & 0 & 0
\end{array}\right] \\
& \mathbf{B}=\left[\begin{array}{llll}
0 & \frac{1}{m} & 0 & 0 \\
\frac{\beta}{V} & 0 & 0 & 0
\end{array}\right] \\
& \mathbf{F}=\left[\begin{array}{lll}
f_{1} \\
f_{2}
\end{array}\right] \\
& \mathbf{C}=\left[\begin{array}{llll}
1 & 0 & 0 & 0
\end{array}\right] \\
& \mathbf{D}=0 .
\end{aligned}
$$

The model is a system with two inputs and one output, and the stability of the system is merely related to matrix A. Furthermore, by putting fixed parameters shown in Table 1 into formula (10) and taking the determinant of $s \mathbf{I}-\mathbf{A}$, the characteristic equation of the system can be obtained:

$$
f(s)=\operatorname{det}(s \mathbf{I}-\mathbf{A})=s^{4}+a_{1} s^{3}+a_{2} s^{2}+a_{3} s+a_{4},
$$

where

$$
\begin{aligned}
a_{1}= & 4.7543 \times 10^{18} \delta_{1}^{3}+2.3177 \times 10^{18} \delta_{2}^{3} \\
& +\frac{5.1051 \times 10^{-6}}{\delta_{1}}+\frac{3.7669 \times 10^{-6}}{\delta_{2}}+1.5844 \\
& \times 10^{1}
\end{aligned}
$$

$$
\begin{aligned}
a_{2}= & 7.5328 \times 10^{19} \delta_{1}^{3}+3.6722 \times 10^{19} \delta_{2}^{3}+2.4271 \\
& \times 10^{13} \delta_{1}^{2}+8.7376 \times 10^{12} \delta_{2}^{2} \\
& +\frac{1.7923 \times 10^{13} \delta_{1}^{3}}{\delta_{2}}+\frac{1.1832 \times 10^{13} \delta_{2}^{3}}{\delta_{1}} \\
& +\frac{8.0886 \times 10^{-5}}{\delta_{1}}+\frac{5.9731 \times 10^{-5}}{\delta_{2}}+7.5071 \\
& \times 10^{8} \\
a_{3}= & 2.4263 \times 10^{25} \delta_{1}^{3}+1.1828 \times 10^{25} \delta_{2}^{3}+3.8456 \\
& \times 10^{14} \delta_{1}^{2}+1.3844 \times 10^{14} \delta_{2}^{2} \\
& +\frac{2.8398 \times 10^{14} \delta_{1}^{3}}{\delta_{2}}+\frac{1.8747 \times 10^{14} \delta_{2}^{3}}{\delta_{1}} \\
& +1.3328 \times 10^{10} \\
a_{4}= & 7.2015 \times 10^{27} \delta_{1}^{3}+3.5108 \times 10^{27} \delta_{2}^{3} .
\end{aligned}
$$

According to the Routh Stability Criterion, if all coefficients in the characteristic equation are positive and the signs of all elements in the first column of Routh Table are positive, the system is stable. With formulae (14)-(15), it can be known that every coefficient of the characteristic equations is positive if $\delta_{1} \in[0,0.02 \mathrm{~mm}]$ and $\delta_{2} \in[0,0.02 \mathrm{~mm}]$. As a fourth-order equation for formula (14), the relief valve will be stable under the condition that signs of $s^{2}$ and $s^{1}$ in the first column of Routh Table are positive. To examine the stability of the relief valve at the ocean depth of $0-4000 \mathrm{~m}$, we need to put fitting clearances at different ocean depths into formula (15). As shown in Figure 6, the coefficients in the first column of $s^{2}$ and 


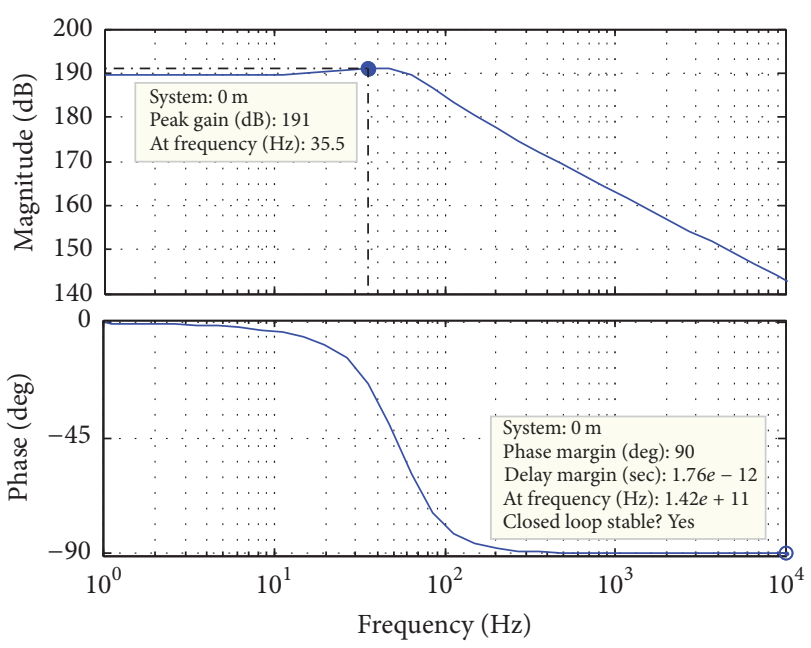

FIGURE 7: BODE diagram of the relief valve in initial conditions.

$s^{1}$ in the Routh Table have changed over various ocean depths, and two coefficients within the ocean depth of $0-4000 \mathrm{~m}$ are all positive values. Therefore, it can be confirmed that this relief valve is stable at ocean depths of $0-4000 \mathrm{~m}$.

3.2. Relative Stability Analysis. The relative stability analysis gives the degree of stability of a stable system, which shows the margin when the system gets unstable. The relative stability analysis of the relief valve is also conducted.

In a practical system, a relief valve is often installed at the output of a pump, which means that the output flow of the pump is the input flow of the valve when all the flow of the pump is relieved by the relief valve. In formula (12), $f_{1}$ and $f_{2}$ are, respectively, seen as equivalent precompressed spring length and input flow of pump. Because the precompressed spring length is a definite value without affecting the stability of the system, the system can be simplified to a single-input one as follows:

$$
\mathbf{B}^{\prime}=\left[\begin{array}{llll}
\frac{\beta}{V} & 0 & 0 & 0
\end{array}\right]^{T} .
$$

The transfer function of the system can be obtained as follows:

$$
\mathbf{G}_{2}(s)=\frac{\mathbf{Y}(s)}{\mathbf{F}_{2}(s)}=\mathbf{C}[s \mathbf{I}-\mathbf{A}]^{-1} \mathbf{B}^{\prime} .
$$

According to the transfer function, we can obtain the BODE diagram of the relief valve in the initial conditions (i.e., $0 \mathrm{~m}$ ocean depth, fitting clearance without deformation) shown in Figure 7. It can be seen from the figure that the values of phase and magnitude margin of the relief valve are positive in initial conditions and also with ample margins, which shows that this valve operating on the surface of sea has a good relative stability.

Putting deformation data of the damping bar and damping sleeve into formula (17), the BODE diagram of the relief valve at different ocean depths can be obtained in Figure 8.
TABLE 2: Dynamic characteristics of seawater relief valve under different ocean depths.

\begin{tabular}{lcccc}
\hline Depth $(\mathrm{m})$ & Rise time (s) & $\begin{array}{c}\text { Overshoot } \\
(\%)\end{array}$ & Peak time (s) & $\begin{array}{c}\text { Setting } \\
\text { time }(\mathrm{s})\end{array}$ \\
\hline 0 & 0.0034 & $16.8 \%$ & 0.0077 & 0.0130 \\
400 & 0.0033 & $23.3 \%$ & 0.0078 & 0.0141 \\
800 & 0.0032 & $30.8 \%$ & 0.0084 & 0.0228 \\
1300 & 0.0031 & $41.2 \%$ & 0.0083 & 0.0276 \\
2500 & 0.00295 & $75.3 \%$ & 0.01058 & 0.0500 \\
\hline
\end{tabular}

From the figure, it can be seen that the peak gain of the relief valve gradually increases with greater ocean depth. Since the $0 \mathrm{~Hz}$ gains of the relief valve at different ocean depths are similar to each other, it can be concluded that the overshoot of the relief valve will increase with greater ocean depths.

Moreover, the value of phase and magnitude margin of the relief valve can be positive and simultaneously with ample margins at the ocean depths shown in Figure 8, so the fitting clearance changes of the damping bar and sleeve caused by huge pressure have a little influence on the relative stability of the relief valve.

\section{Performances Simulation of Relief Valve under Different Ocean Depths}

4.1. Dynamic Characteristics Simulation with Step Flow Input. On the basis of the structural parameters given above, the dynamic characteristic of the relief valve on the initial condition (i.e., $0 \mathrm{~m}$ ocean depth) can be obtained as shown in Figure 9. From the stimulation data, it can be calculated that the rise time $t_{r}=0.0034 \mathrm{~s}$, peak time $t_{p}=0.0077 \mathrm{~s}$, overshoot $M_{p}=16.8 \%$, setting time $t_{s}=0.0130 \mathrm{~s}$, and the value of control precision is 0.95 .

With the ocean depth increasing, the fitting clearances of damping bar and sleeve will gradually decrease, and the changes of clearances are bound to have great influences on the dynamic characteristics of the valve. Putting the fitting clearances after deformation into the simulation model, the dynamic characteristics at different depths can be gotten as shown in Table 2. From the simulation results, the rise time of the valve will decrease slightly with the increase of ocean depths, but the overshoot will increase, which is up to $75.3 \%$ when the valve works at $2500 \mathrm{~m}$ ocean depth. Moreover, excessive amount of overshoot will increase the adjustment time of the relief valve to achieve stable pressure with the increase of ocean depth.

\subsection{Dynamic Characteristics Simulation with Pulsating Flow} Input. The valve has been successfully applied to an underwater tool system. In this system, the valve is placed at the pump outlet. To detect the dynamic performance of the valve, the output flow of the pump is regarded as the input flow of the valve. Therefore, considering the flow ripple of the 

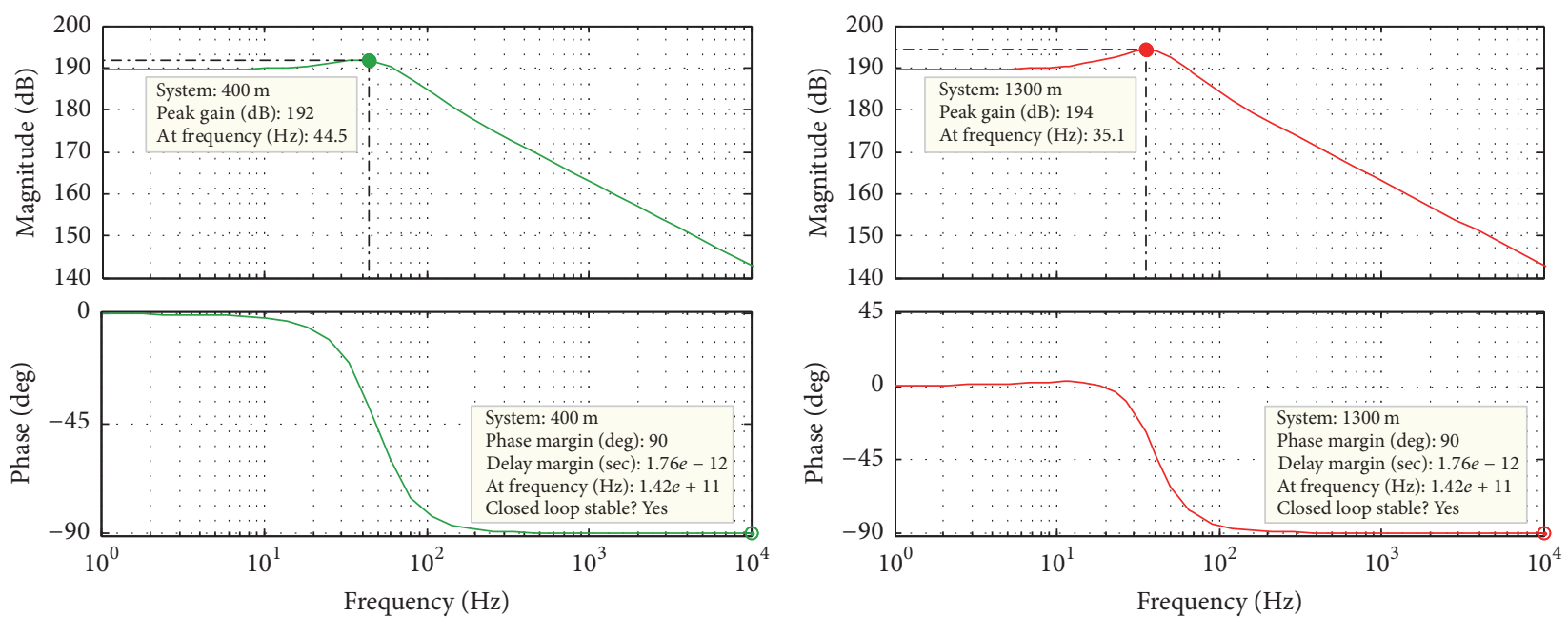

(a) $400 \mathrm{~m}$ ocean depth

(b) 1300 m ocean depth

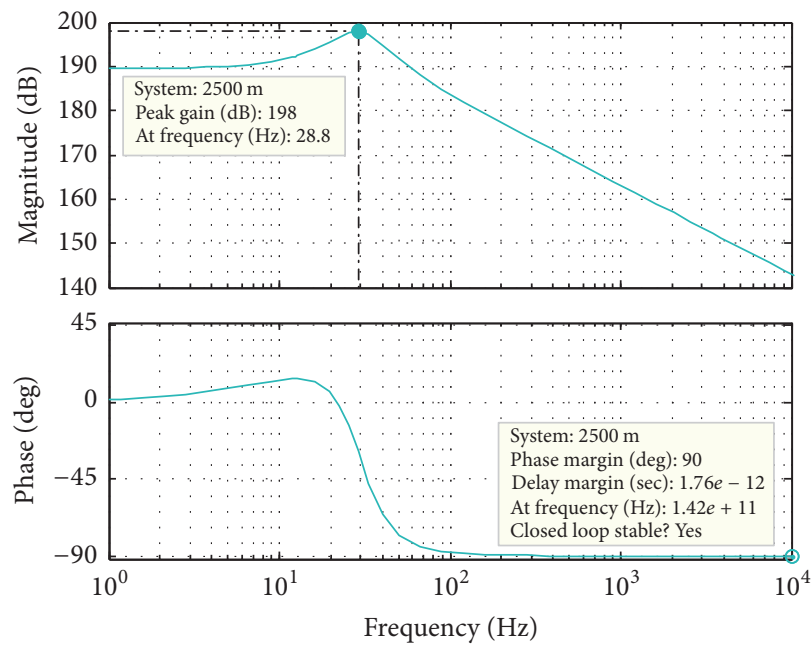

(c) 2500 m ocean depth
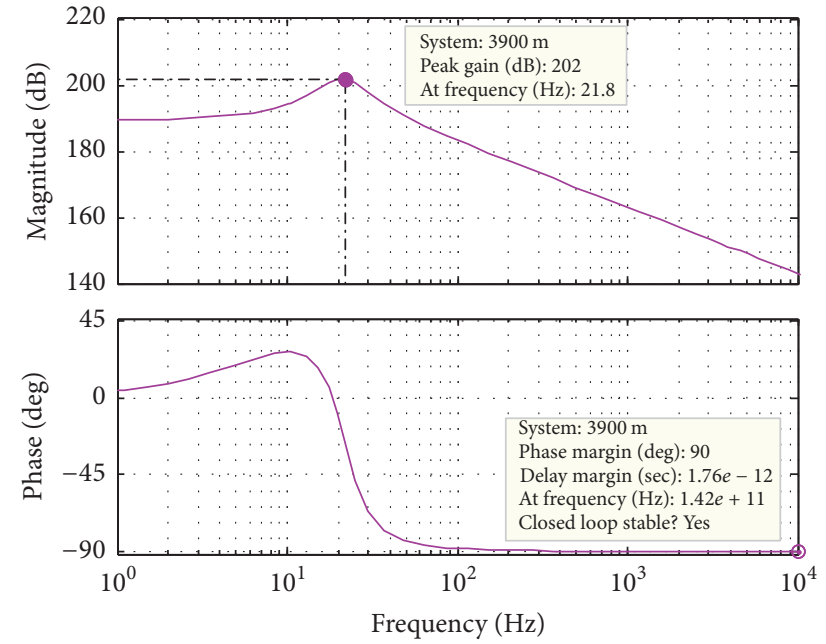

(d) 3900 m ocean depth

FIGURE 8: BODE diagrams of the relief valve under environment of different ocean depths.

plunger pump, the real-time output flow of a plunger pump can be obtained as

$$
\begin{aligned}
q_{\mathrm{sh}}= & \frac{V}{2 z} 2 \pi n \sum_{i=1}^{z} \sin \varphi_{i} \\
\sum_{i=1}^{z} \sin \varphi_{i}= & \sin (2 \pi n t)+\sin (2 \pi n t+2 \alpha)+\cdots \\
& +\sin [2 \pi n t+2 \alpha(z-1)],
\end{aligned}
$$

where $V$ is the displacement of the plunger pump $(40 \mathrm{~mL} / \mathrm{r}) ; z$ is the number of plungers of the pump (5); $n$ is the rated speed of the pump (750 r/min); $2 \alpha$ is the central angle between two plungers of the pump, and $2 \alpha=2 \pi / z$.

Ignoring the influences of friction, corrosion, cavitations, strain, and other factors of the valve, the simulation results with design clearance are shown in Figure 10. Compared with Figure 9, it can be seen that the main dynamic characteristics of the system under pulsating flow input are in accordance with the performance under ideal input condition, while pressure response will be accompanied by a small pulsation at last. Fortunately, simulation results show that the valve has a good anti-interference ability.

Figure 11 is the pressure response with pulsating flow at different ocean depths. Compared with the response with constant flow (shown in Figure 9), it can be figured out that the decrease of fitting clearance resulting from pressure of ocean depth does not reduce the anti-interference ability of the seawater relief valve. At the same time, the pressure pulsation of the valve caused by flow pulsation is similar to the performance of the initial clearance, without the increasing oscillation or divergence. Thus, simulation results give evidence to the stability of the relief valve.

\section{Conclusions}

In this paper, a direct-operated seawater hydraulic relief valve with a damping device is introduced. The mathematical 


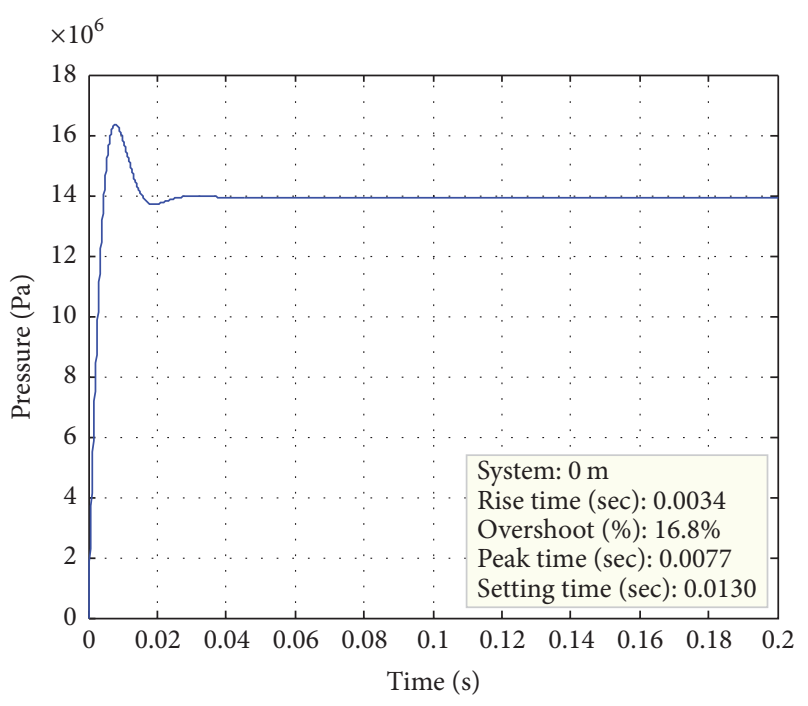

FIGURE 9: Dynamic characteristics $P$ - $T$ curve of seawater relief valve in initial conditions.

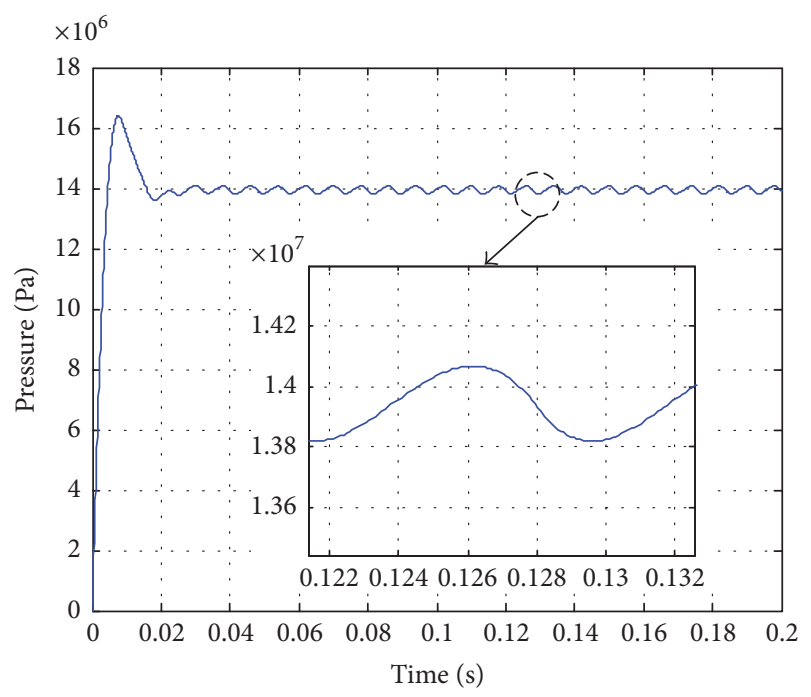

Figure 10: Dynamic P-T curve of seawater relief valve under pulsating flow input (ocean depth of $0 \mathrm{~m}$ ).

model of the valve is derived, in which the fitting clearance between the damping sleeve and damping bar $\left(\delta_{1}, \delta_{2}\right)$ has a great effect on the dynamic stability. Considering the deformation of the damping sleeve and bar due to huge environmental pressure, the deformation simulation of the damping sleeve and bar at different ocean depths is achieved and different fitting clearances over varying depths are obtained. Based on the results obtained from the deformation simulation, the following conclusions can be made:

(1) Because of the deformation of the damping sleeve and bar, the relief valve has an effective working depth and it will fail to work at a greater depth. This is because the fitting clearance, that is, the clearance between the damping sleeve and bar, will decrease with the increase of the working depth. If the deformation is larger than the initial clearance, the moving parts of the valve will be stuck. Actually, this is a common problem for the components with precise clearance of matching pairs, such as piston/sleeve in a hydraulic pump, spool/sleeve in a hydraulic valve, and bearings in an electric motor, which must be considered in design.

(2) For the relief valve above, the damping device is an important part and the clearance between the damping sleeve and bar is a depth sensitive parameter. When the depth is $4000 \mathrm{~m}$, the clearance is $0 \mathrm{~mm}$ and the valve is invalid. Considering a certain safe margin, the working depth is $3500 \mathrm{~m}$ or less.

(3) Although the fitting clearance becomes less with the increase of working depth, the relief valve is still stable according to the stability analysis.

(4) The resonance peak of the relief valve in the relative stability analysis, which is positively correlated to the overshoot of the relief valve, increases with greater and greater ocean depth. And the relative stability analysis shows that relief valve always keeps an ample positive phase and magnitude margin within the depths of $0-4000 \mathrm{~m}$.

(5) The overshoot of the relief valve of step response increases with the increase of the ocean depth, and larger overshoot results in a longer setting time of the relief valve. Considering the $30 \%$ maximum overshoot of the criterion for land used relief valves, the maximum ocean depth of the relief valve suited for normal work is approximately $800 \mathrm{~m}$. Irrespective of the $75.3 \%$ overshoot of the relief valve at $2500 \mathrm{~m}$ ocean depth, the relief valve still can achieve the desired stable pressure with a very short time.

(6) It can be figured out that the decrease of fitting clearance resulting from the pressure of ocean depth does not reduce the anti-interference ability of the seawater relief valve. The pressure pulsation of the relief valve in deep sea, which is caused by the flow pulsation of piston pump, is similar to the situation with the initial clearance. And all the situations do not exhibit increasing oscillation or divergence.

The conclusions drawn in this paper not only offer guidelines for the selection or design of a direct-operated seawater hydraulic relief valve used in deep sea, but also provide the references for analyzing other types of hydraulic control components, such as flow pressure compensated control valves, pressure relief valves, or pilot relief valves, since those valves all can be abstracted as a coupling system of spring-mass and liquid accompanied by the stable problem. Moreover, this paper has also provided an analysis method, 


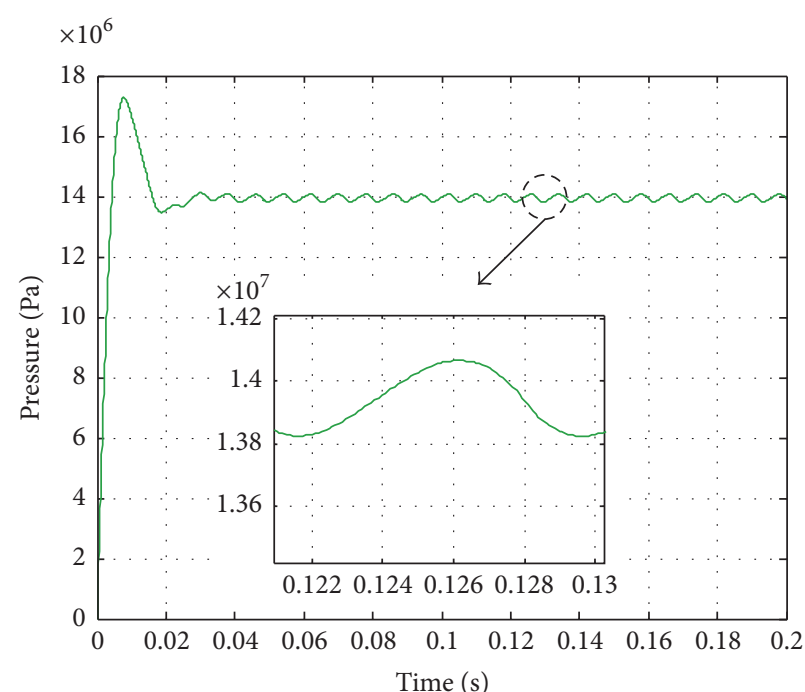

(a) $400 \mathrm{~m}$ ocean depth

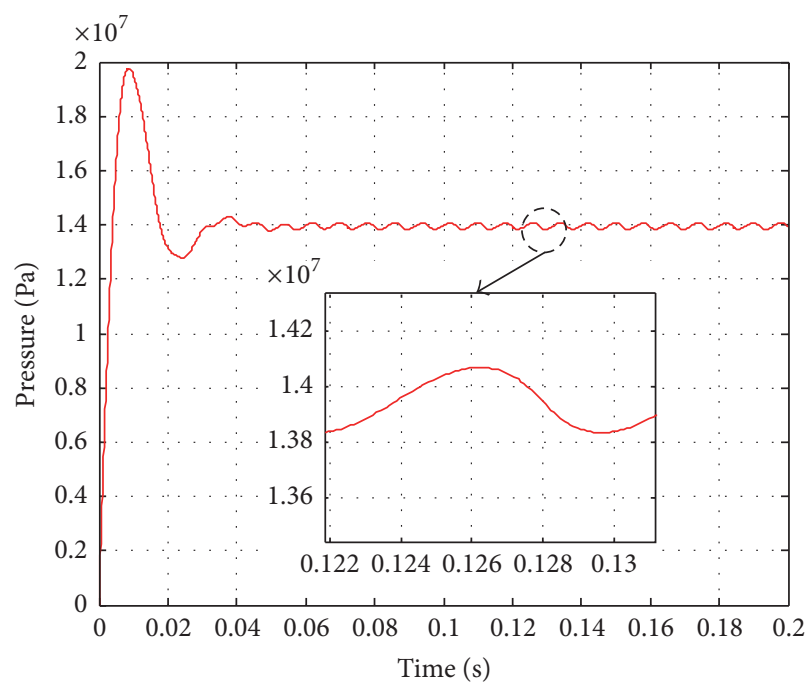

(c) 1300 m ocean depth

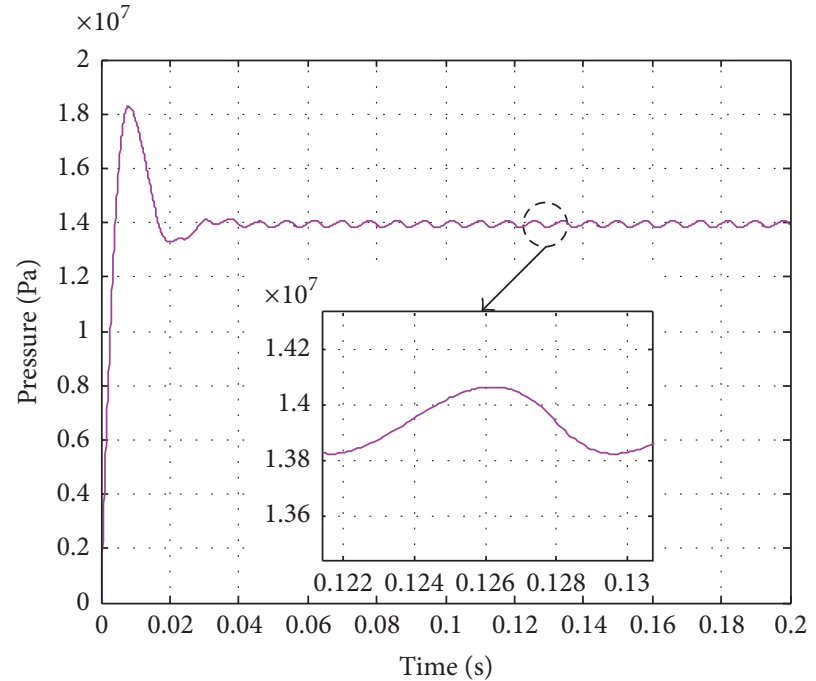

(b) $800 \mathrm{~m}$ ocean depth

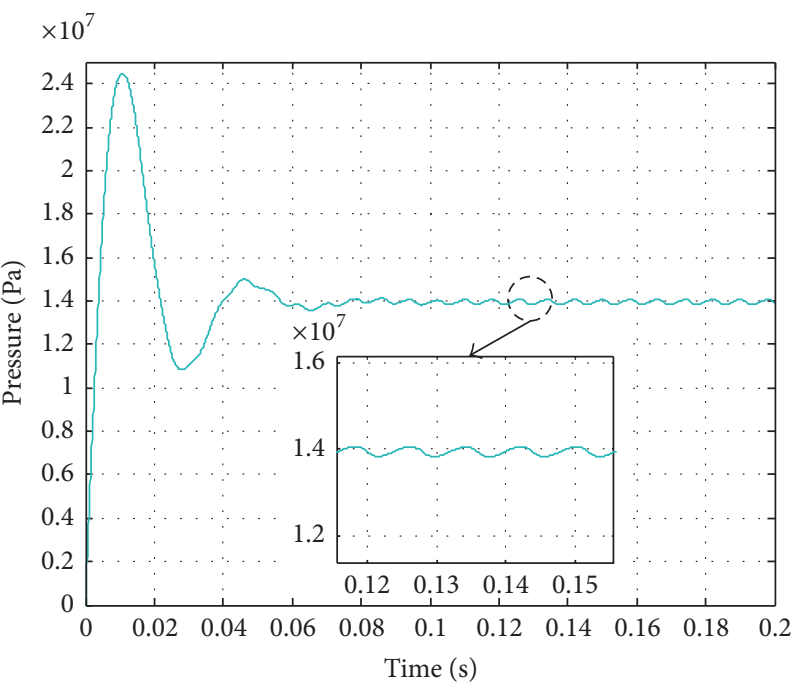

(d) 2500 m ocean depth

FIGURE 11: Dynamic P-T curves of seawater relief valve at different ocean depths under pulsating flow input.

which puts deformation data of key fitting clearances of hydraulic components at different ocean depths into a statespace model for underwater hydraulic system.

\section{Conflicts of Interest}

The authors declare that they have no conflicts of interest regarding the publication of this paper.

\section{Acknowledgments}

This paper is supported by the Program for Science Research from Education Department of Hubei Province (B2014168) and Wuhan Technology and Business University (B2013005), New Century Excellent Talents in University (NCET-13-0231), National Sci-Tech Support
Plan (2014BAB12B00), and National Key R\&D Plan (2016YFC0304800\&2016YFC0300600).

\section{References}

[1] B. Xin, L. Xiaohui, S. Zhaocun, and Z. Yuquan, "A vectored water jet propulsion method for autonomous underwater vehicles," Ocean Engineering, vol. 74, pp. 133-140, 2013.

[2] Y. Liu, X. Zhao, D. Wu, D. Li, and X. Li, "Study on the control methods of a water hydraulic variable ballast system for submersible vehicles," Ocean Engineering, vol. 108, pp. 648-661, 2015.

[3] X. Zhao, Y. Liu, M. Han, D. Wu, and D. Li, "Improving the performance of an AUV hovering system by introducing lowcost flow rate control into water hydraulic variable ballast system," Ocean Engineering, vol. 125, pp. 155-169, 2016. 
[4] Y. Liu, D. Wu, D. Li, X. Zhao, and X. Li, "Applications of seawater hydraulics in deep-sea equipment," Journal of Mechanical Engineering, vol. 50, no. 2, pp. 28-35, 2014.

[5] D. Wu, Y. Liu, D. Li, X. Zhao, and Y. Liu, "Tribo-corrosion properties of WC-10Co-4Cr coating in natural silt-laden waters when sliding against Si3N4," International Journal of Refractory Metals and Hard Materials, vol. 58, pp. 143-151, 2016.

[6] D. Wu, Y. Liu, X. Zhao, D. Li, and X. Ren, "The tribological behaviors of different mass ratio $\mathrm{Al} 2 \mathrm{O} 3-\mathrm{TiO} 2$ coatings in water lubrication sliding against Si3N4," Tribology Transactions, vol. 59, no. 2, pp. 352-362, 2016.

[7] D. Wu, Y. Liu, D. Li, X. Zhao, and X. Ren, "The applicability of WC-10Co-4Cr/Si3N4 tribopair to the different natural waters," International Journal of Refractory Metals \& Hard Materials, vol. 54, pp. 19-26, 2016.

[8] D. Wu, Y. Liu, D. Li, and X. Zhao, "Effect of materials on the noise of a water hydraulic pump used in submersible," Ocean Engineering, vol. 131, pp. 107-113, 2017.

[9] J. Liang, X. Luo, Y. Liu, X. Li, and T. Shi, "A numerical investigation in effects of inlet pressure fluctuations on the flow and cavitation characteristics inside water hydraulic poppet valves," International Journal of Heat and Mass Transfer, vol. 103, pp. 684-700, 2016.

[10] K. Dasgupta and R. Karmakar, "Modelling and dynamics of single-stage pressure relief valve with directional damping," Simulation Modelling Practice and Theory, vol. 10, no. 1-2, pp. 51-67, 2002.

[11] K. Dasgupta and R. Karmakar, "Dynamic analysis of pilot operated pressure relief valve," Simulation Modelling Practice and Theory, vol. 10, no. 1-2, pp. 35-49, 2002.

[12] C. Bazsó and C. J. Hos, "An experimental study on the stability of a direct spring loaded poppet relief valve," Journal of Fluids and Structures, vol. 42, pp. 456-465, 2013.

[13] K. Suzuki and E. Urata, "Development of a direct pressuresensing water hydraulic relief valve," International Journal of Fluid Power, vol. 9, no. 2, pp. 5-13, 2008.

[14] S. Hayashi, A. Shirai, N. N. Guo, and T. Hayase, "Static and dynamic characteristics of a pressure-compensated flow control," in Proceedings of the 5th International Conference on Fluid Power Transmission and Control (ICFP '01), pp. 425-429, Hangzhou, China, 2001.

[15] B. Wolfgang, "Water or oil hydraulics in the future," in Proceedings of 6 th Scandinavian International Conference on Fluid Power, pp. 51-64, Tampere, Finland, 1999.

[16] R. D. Eyres, A. R. Champneys, and N. A. J. Lieven, "Modelling and dynamic response of a damper with relief valve," Nonlinear Dynamics, vol. 40, no. 2, pp. 119-147, 2005.

[17] X. Luo, X. He, S. Cao, and X. Ba, “Theoretical and experimental analysis of a one-stage water hydraulic relief valve with a oneway damper," Journal of Pressure Vessel Technology, vol. 135, no. 6, Article ID 061210, 2013.

[18] R. Darby, "The dynamic response of pressure relief valves in vapor or gas service, part I: mathematical model," Journal of Loss Prevention in the Process Industries, vol. 26, no. 6, pp. 1262-1268, 2013.

[19] C. J. Hos, A. R. Champneys, K. Paul, and M. McNeely, "Dynamic behaviour of direct spring loaded pressure relief valves in gas service: II reduced order modelling," Journal of Loss Prevention in the Process Industries, vol. 36, pp. 1-12, 2015.

[20] K. Dasgupta and J. Watton, "Dynamic analysis of proportional solenoid controlled piloted relief valve by bondgraph," Simulation Modelling Practice and Theory, vol. 13, no. 1, pp. 21-38, 2005.
[21] A. Zanj, H. Karimi, A. J. Gholi, and M. Shafiee, "Dynamic modeling of indirect hydro-control valve-Bondgraph approach," Simulation Modelling Practice and Theory, vol. 28, pp. 65-80, 2012.

[22] F. Yuan and X. Wu, "Hydrostatic pressure effects on deformation mechanisms of nanocrystalline fcc metals," Computational Materials Science, vol. 85, pp. 8-15, 2014.

[23] Q. Ye and J. Chen, "Dynamic analysis of a pilot-operated twostage solenoid valve used in pneumatic system," Simulation Modelling Practice and Theory, vol. 17, no. 5, pp. 794-816, 2009.

[24] L. Yinshui, R. Xiaojun, W. Defa, L. Donglin, and L. Xiaohui, "Simulation and analysis of a seawater hydraulic relief valve in deep-sea environment," Ocean Engineering, vol. 125, pp. 182190, 2016

[25] G. E. Totten and V. J. De Negri, Handbook of Hydraulic Fluid Technology, CRC Press, 2nd edition, 2012. 


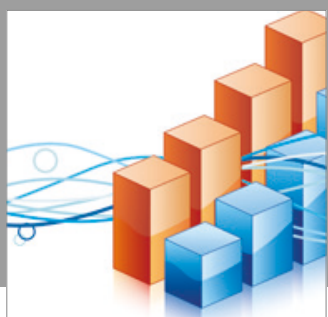

Advances in

Operations Research

vatersals

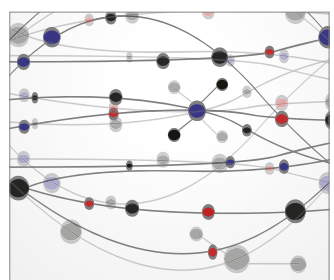

\section{The Scientific} World Journal
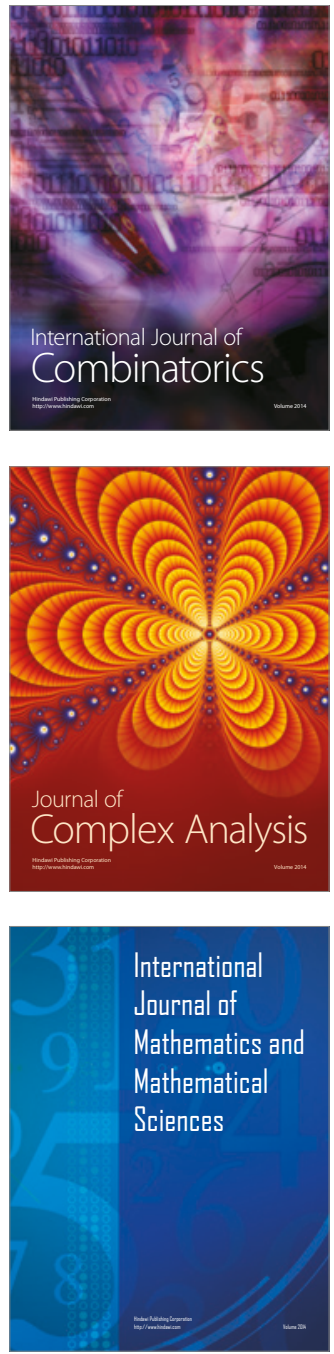
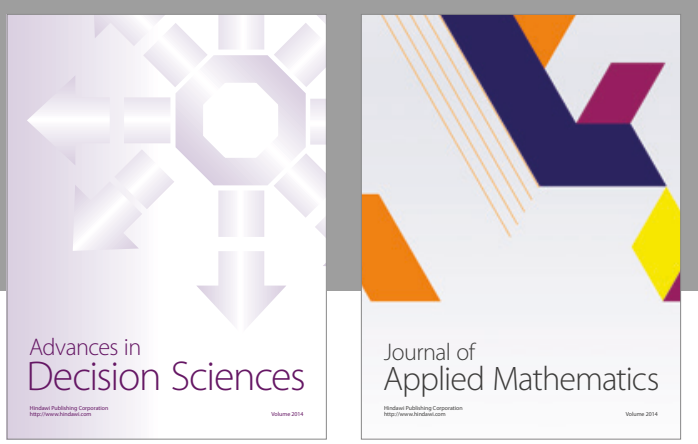

Algebra

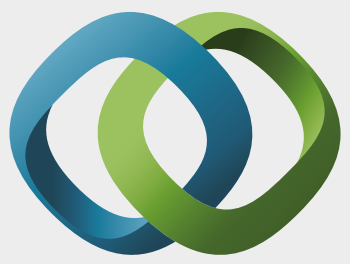

\section{Hindawi}

Submit your manuscripts at

https://www.hindawi.com
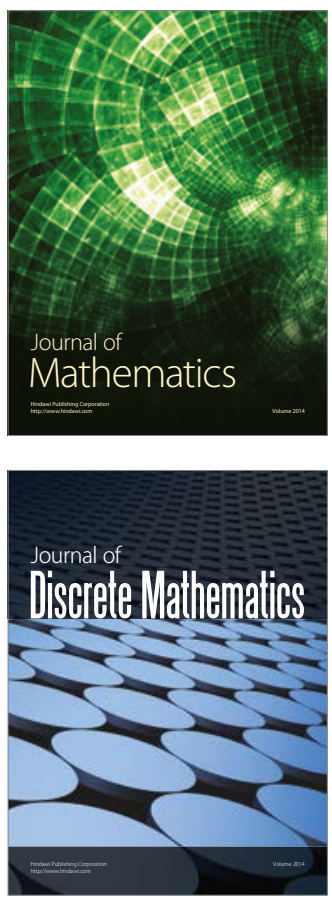

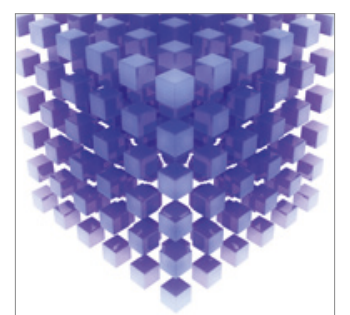

Mathematical Problems in Engineering
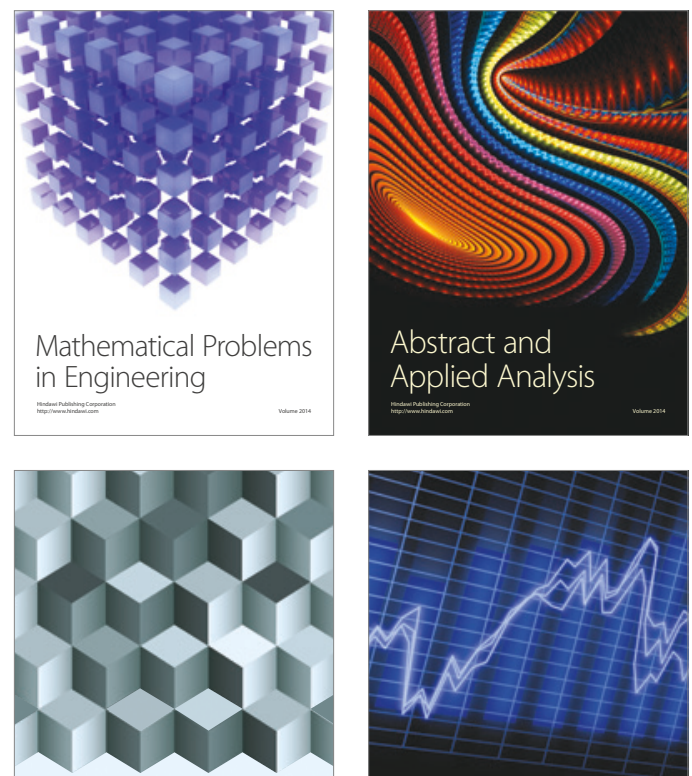

Journal of

Function Spaces

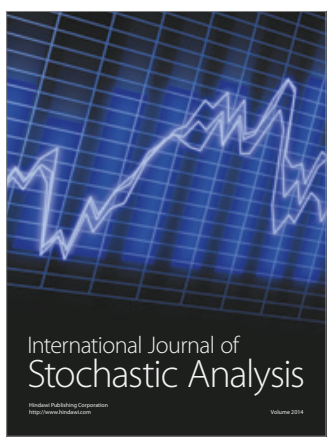

Probability and Statistics
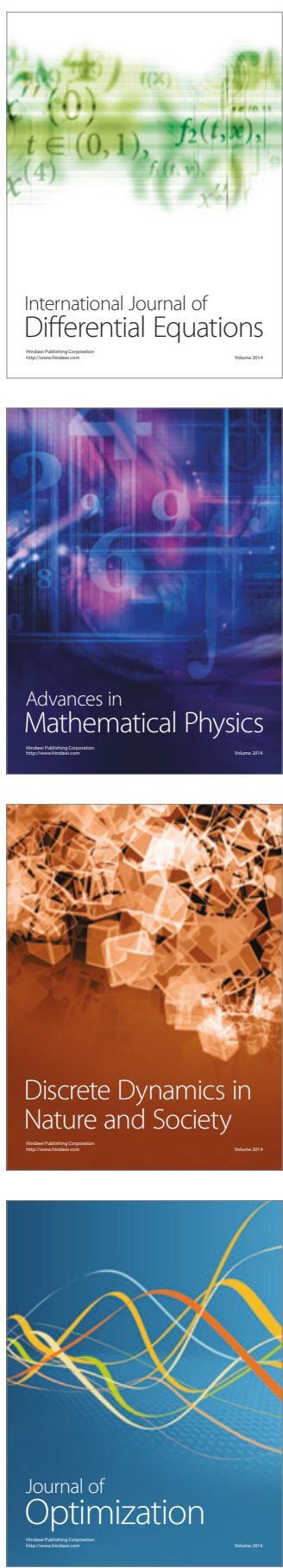